\title{
MODIFICACIONES AL CÓDIGO DE COMERCIO CHILENO: ARTÍCULO 513 INCISO SEGUNDO - EL RIESGO
}

\author{
MODIFICATION OF THE CHILEAN COMMERCE CODE: \\ ARTICLE 513 SECOND PARAGRAPH - THE RISK
}

\section{ROBERTo Ríos OSSA*}

\begin{abstract}
RESUMEN: La escasa doctrina nacional en materia de regulación sobre seguros, ha sostenido una fuerte crítica a lo dispuesto en el inciso segundo del artículo 513 del Código de Comercio, norma que, al contener la expresión caso fortuito hace insuficiente la definición de riesgo, lo que implicaría que el contrato de seguro no podría amparar actuaciones culposas del asegurado, o actos dolosos o culposos de terceros. Ello nos llevaría a una consecuencia desastrosa, como la de excluir todas las pólizas de responsabilidad civil depositadas en la Superintendencia de Valores y Seguros. En este trabajo, recurriendo al método histórico crítico y a la comparación de derechos, concluiremos que la asegurabilidad de hechos culposos del asegurado, y hechos dolosos o culpables de terceros, no constituyen una infracción a la citada norma legal, y se pueden asegurar por pacto expreso entre el asegurador y el asegurado.
\end{abstract}

Palabras clave: riesgo asegurable, caso fortuito, culpa, dolo, responsabilidad civil.

ABSTRACT: The limited Chilean doctrine of the matter to the regulation of insurance has held a strong criticism to the second paragraph of the article 513 of the commerce code. If this is a law that contains an act of god's expression, it is not enough to define the risk. This implies that the insurance contract cannot protect negligent acts for the insured or negligent and intentional acts for a third party. This would lead to a disastrous consequence, such as excluding all the civil liability policies deposited in the Values and Insurance Superintendence. In this work, appealing to the critical historical method and comparative law rights, we would conclude that the negligent acts of the insured and negligent or intentional acts to a third party would not break this law and can be insured by expressed pact or agreement.

Key words: insurance risk, act of god, negligent, deceitfulness, torts.

\section{INTRODUCCIÓN}

Son varios los proyectos de ley que han pretendido modificar el Título VIII, del Libro Segundo de nuestro Código de Comercio, sobre EI Seguro en General y de los Seguros Terrestres en Particular.

Las razones que se han expuesto en foros, seminarios y algunas publicaciones coinciden en lo siguiente: "El Código de Comercio está obsoleto, alejado de la realidad de la industria del seguro".

Lo anterior aparece claramente expuesto en el mensaje del proyecto que 
actualmente se tramita en nuestra Cámara de Diputados, el que fue elaborado por el profesor y abogado Osvaldo Contreras Strauch. Parte del mensaje señala:

"Cuando el 5 de octubre de 1865, el Presidente Don José Joaquín Pérez envió al Congreso Nacional el proyecto de ley sobre Código de Comercio, al referirse al Título VIII de su Libro II, sobre contrato de seguro, no pudo dejar de hacer presente en el Mensaje, con orgullo, que bastará para excitar vuestra atención el conocimiento de que muchas de las naciones europeas carecen hasta hoy de leyes sobre esta importante materia y que ella es completamente nueva en el país. Este comentario era rigurosamente cierto" 1.

Pero han transcurrido desde esa fecha más de ciento cuarenta años y todavía siguen rigiendo dichas normas, sin modificación ni actualización alguna, a pesar de que el seguro ha experimentado una notable evolución a escala nacional y mundial, de tal modo que poco a poco la realidad contractual se fue distanciando del contenido de las normas del Código de Comercio, las que en algunos casos se convirtieron en insuficientes, erróneas o decididamente inaplicables.

Llevado de la mano por la libertad contractual, que preside todo el derecho privado, el contrato de seguro fue supliendo esas carencias, sobre la base de las estipulaciones contenidas en las cláusulas de las pólizas, hasta tal punto que llegó un momento en que se formó una realidad jurídica al margen de las normas del Código².

Desde hace muchos años los agentes del mercado de seguros y los especialistas han venido propiciando la urgente necesidad de actualizarlas, poniendo de relieve que en esta materia el divorcio entre la ley y la realidad económica es fuerte hasta tal punto, que se han ido formando costumbres que van, incluso, contra el texto expreso de la ley, pero que son estrictamente observadas por las partes, porque los contratos que se ajustan a dichas costumbres, pero no a la ley, obedecen a una necesidad económica práctica imperativa.

En el presente trabajo efectuaremos un análisis del artículo 513 del Código de Comercio, específicamente su inciso segundo que define el riesgo. Trataremos de elaborar una tesis que permita mantener incólume el texto actual de la citada norma, y proponer una reinterpretación de la misma.

Para poder descubrir y luego entender la definición que ha dado Ocampo al elemento del riesgo en el artículo 513 del Código de Comercio, hemos elaborado un plan de trabajo que comprende un breve análisis de la doctrina y legislación contemporáneas a la elaboración y dictación de nuestro código ${ }^{3}$. Recurriremos además, a la comparación de derechos, con el fin de poder determinar finalmente si la insuficiencia normativa de la que es acusado nuestro Código de Comercio -en este caso tomando como ejemplo el artículo 513- es una afirmación correcta.

A su vez, advertimos que no incluiremos en este breve trabajo, el concepto de riesgo y su teorización al tenor de lo dispuesto en el artículo 1550 del Código Civil, por considerar que apuntan a situaciones jurídicas con efectos diferentes ${ }^{4}$. 


\section{BREVE ANÁLISIS DE FUENTES EPIGONALES}

Advertimos en primer lugar, que a diferencia del nuestro Código Civil, del Código de comercio conocemos solo un proyecto del 1856, cuyo texto contempla un Título VIII denominado como Del Seguro en General y De los Seguros Terrestres en Particular, artículos 656 a 734. La única diferencia que encontramos -ello centrándonos en el análisis de la definición de riesgo- está dada en la numeración del articulado; en el actual texto del código, el riesgo está definido en el artículo 513, en el proyecto está definido en el artículo 657 . En cuanto a la redacción ambos son idénticos. ¿Cuáles habrán sido las fuentes epigonales que influyeron en Ocampo en la redacción del artículo 513 inciso segundo?

Siguiendo la recopilación de las notas al proyecto de Código de Comercio, obra del Historiador y Abogado chileno Enrique Brahm García, al margen del inciso segundo del artículo 657 del primer borrador, se hace referencia como fuente a Huebra. Se trata de Pablo González Huebra, un jurista español del siglo XIX, Catedrático de la asignatura de derecho mercantil de las Universidades de Madrid, Salamanca y Barcelona, quien escribió varias obras de Derecho Mercantil, entre ellas una denominada Curso de Derecho Mercantil, que trata entre otras instituciones el contrato de seguros. Siguiendo a este autor no cabe duda que Ocampo lo tomó como fuente epigonal doctrinaria. González Huebra dice: "Se llama asegurador al que toma el riesgo sobre sí; y al que queda libre de el asegurado" 5 . Nuestro Código de Comercio en el inciso primero del artículo 513 dispone: "llámase asegurador la persona que toma por su cuenta el riesgo, asegurado al que queda libre de él" (en el proyecto artículo 657).

Siguiendo a González Huebra, específicamente en la definición de riesgo, no encontramos una similitud como la enunciada en el párrafo anterior. Este autor al tratar el riesgo lo define: "por riesgo entendemos todos los accidentes que puedan ocurrir (...)"; la expresión caso fortuito que de manera expresa usa Ocampo en nuestro Código, no aparece en la obra de González Huebra. Ello a pesar que hay otros autores contemporáneos a este jurista, que sí utilizan el término caso fortuito, como Pablo Avecilla en su Diccionario de Legislación Mercantil de España 6 .

Luego, y recurriendo nuevamente a la recopilación de Brahm García, encontramos al margen del primer borrador del código de comercio otra referencia, además del citado González Huebra, que se indica con la sigla D.A.B; sin embargo en la obra del citado historiador no se aclara que significa la sigla citada. Luego de una revisión de obras y autores posteriores al Code de commerce y anteriores a nuestro código, hemos podido determinar que se trata de Alejandro de Bacardí, abogado integrante del llustre Colegio de Barcelona, quien publicó en 1840 la obra titulada "Tratado de Derecho Mercantil de España por D.A.B", obra que contiene un título VIII dedicado a la aseguración. Bacardí señala: "llámase contrato de seguro aquel por el cual uno de los contratantes llamado asegurador se obliga a pagar cierta suma a otro que se llama asegurado en un acta o escritura que se llama póliza de 
seguro, en caso que sucedan ciertos eventos que allí se determinan de un modo más o menos expreso, mediante un precio que se denomina premio o prima del seguro, en recompensa de los riesgos que corre". Este autor define el riesgo de la siguiente manera: "Bajo el nombre de riesgo se entiende aquí cualquier accidente o caso fortuito que pueda ocasionar la entera pérdida o algún otro daño a las cosas aseguradas"7. No cabe duda alguna la similitud de la definición que nos da Bacardí, con el texto del artículo 657 del proyecto y del artículo 513 de nuestro actual código, que dispone: "Se entiende por riesgo la eventualidad de todo caso fortuito que pueda causar la pérdida o deterioro de los objetos asegurados".

Bacardí, a la hora de establecer el alcance del término accidente o caso fortuito, advierte lo siguiente: "El objeto de este contrato es reparar una pérdida posible, así los riesgos forman su esencia. Todos los que sean apreciables y puedan suceder por efecto de fuerza mayor o caso fortuito pueden ser causa de un contrato de seguro". Este autor es contrario a que el asegurador se haga responsable de las pérdidas o daños ocasionados por la culpa del asegurado, ya que ello atenta en contra de los principios generales de los contratos aleatorios; hace extensible este criterio incluso a las pérdidas causadas por individuos de cuya conducta sea responsable el asegurado. Luego señala Bacardí, que en el comercio marítimo existe una excepción, dada por la estipulación especial, pero a su vez señala que tal norma no es aplicable a los seguros terrestres ${ }^{8}$.

Continuando nuestro análisis de la codificación española, recurrimos al Código de Comercio Español de $1829^{9}$, el que contiene una regulación de los seguros de conducciones terrestres (artículos 417 a 426), sin embargo no contiene ninguna norma que nos dé luces en cuanto al alcance del término daño fortuito. Este mismo texto legal contiene además, una regulación del seguro marítimo entre los artículo 840 y 929; el artículo 861 inciso primero hace referencia a la posibilidad de aseguración de daños que provengan de hechos que no sean necesariamente fortuitos; para ello las partes deben pactarlo. A esta excepción es la que se refiere Bacardí, lo que no compartimos es que no se pueda aplicar -por analogía por ejemplo- a los seguros terrestres ${ }^{10}$.

Siguiendo nuestro estudio, recurriremos ahora al jurista español García Goyena, quien en el proyecto de Código Civil español de 1851 incluye los artículos 1966 a 196911. Este autor en su obra Concordancias del Código Civil Español al analizar la redacción del artículo 1966, y específicamente la expresión daño fortuito, señala: "Daño Fortuito: pues si ha acaecido por culpa o falta del propietario, no responde el asegurador; luego dice: ver artículo 1698. Este artículo en su inciso segundo expresa que "la prueba de haber ocurrido el daño por caso fortuito y sin culpa del que la experimentó, incumbe a este". Como podemos ver García Goyena sigue la concepción de Bacardí12.

Sobre la expresión caso o daño fortuito que usa tanto la legislación, como la doctrina española, en los comentarios de la Comisión Revisora del proyecto del Código Civil de 1851, se expresa lo siguiente: "Se encuentra demasiado estrecho el área del contrato de seguro, reducido el riesgo al caso 
fortuito por el artículo 1696. Digno es de ejercer su benéfico influjo cuando la culpa de los hombres causa daños; sin ese ensanche será muy endeble la garantía que se ofrezca a los asegurados, cuyos bienes no están a cubierto de la malicia o perversidad humana" 13 .

Luego, el Código de Comercio Español de 1885, contiene una regulación más extensa que la de su antecesor, el de 1829, sin embargo tampoco encontramos definiciones. Tal deficiencia está suplida por el Código Civil Español de 1888, específicamente en el Título XII, De Los Contratos Aleatorios ${ }^{14}$, artículo 1791. Este artículo es idéntico en su redacción al artículo 1966 del proyecto de García Goyena, ambos expresan lo siguiente: "Contrato de seguro es aquel por el cual el asegurador responde del daño fortuito que sobrevenga en los bienes muebles 0 inmuebles asegurados, mediante cierto precio, el cual puede ser fijado libremente por las partes". Sin embargo, hay una importante diferencia en los artículos 1698 del proyecto de García Goyena y el artículo 1796 del Código Civil de 1888, cual es: este último artículo elimina el inciso segundo del artículo 1698 que disponía que "La prueba de haber ocurrido el daño por caso fortuito y sin culpa del que la experimentó, incumbe a este".

Siguiendo la línea trazada -Bacardí, García Goyena y Código Civil español de 1888- recurriremos al autor español José María Manresa y Navarro, quien en sus comentarios al artículo 1791 del Código Civil español, define al contrato de seguro como aquel en que una de las partes se obliga a responder, mediante cierto precio, del daño fortuito que pueda sobrevenir sobre ciertos bienes determinados de la pertenencia del otro contratante. Luego señala Manresa y Navarro que es aleatorio el contrato de seguro porque responde a uno de los dos fines que pueden tener todos los de esa clase. Según ha dicho un autor, los contratos aleatorios, o tienen por objeto alcanzar un lucro incierto, pero probable, o evitar un riesgo posible, y a la realización de este segundo fin obedece el de seguro en sus diversas especies. Luego este autor nos ilustra con lo siguiente: El contrato de seguro carecía de regulación en la legislación civil del antiguo derecho español ${ }^{15}$, solo se encuentran antecedentes en los proyectos de Código de 1851 y 1882. Continúa este jurista español señalando: "De la definición del contrato de seguro dada por el primero de los artículos objeto de este comentario, se deduce que la responsabilidad alcanza hasta el caso fortuito, pero no el daño intencional, y no puede menos ser así, porque lo contrario estaría en pugna con la naturaleza de los contratos aleatorios, toda vez que el daño intencional no depende del azar, sino de la voluntad del individuo que da origen al mismo"16.

Veremos más adelante la importancia de lo expresado por Manresa Navarro, al señalar que el daño fortuito excluye el daño intencional. Nada dice este autor, del daño que proviene del acto culposo del asegurado. En tal sentido, creemos que la aleatoriedad no se verá amenazada por un acto voluntario negligente, si por un acto intencional o deliberado, ya que ello sin duda alguna elimina la incertidumbre, la contingencia incierta de ganancia o pérdida. 
Recurriendo a nuestro Código Civil, título XXXIII De los Contratos Aleatorios, el artículo 2258 dispone: Los principales contratos aleatorios son:

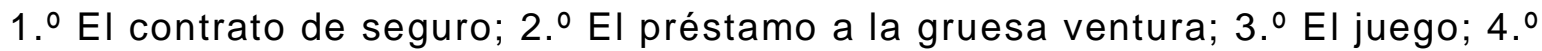
La apuesta; 5. La constitución de renta vitalicia; $6 .$. La constitución del censo vitalicio. Los dos primeros pertenecen al Código de Comercio.

La concordancia del artículo 2258 del código de Bello y el artículo 1964 del Code Civil des Francais es evidente (tal concordancia de da también en el artículo 1790 del Código Civil Español de 1888); la diferencia está solamente en que el Code Civil des Francais define el contrato aleatorio.

En atención a nuestro análisis anterior, consideramos necesario ir más allá, y determinar cuáles fueron las posibles fuentes epigonales que influyeron en González Huebra y Bacardí. Recurriremos para ello a la codificación francesa, que influyó en toda la codificación europea. Así, llegamos al Código de Comercio Francés, verificando que tal texto legal reglamenta al seguro marítimo en los artículos 332 a 397 y contiene un breve apéndice, a continuación del singularizado articulado, que hace referencia muy genérica a los seguros terrestres ${ }^{17}$. No encontramos ninguna definición de riesgo como la contenida en nuestro código. Sin embargo y como ya señalamos, recurriendo al Códe Civil encontramos en el Título XII, De los Contratos Aleatorios, el artículo 1964 que dice: "El contrato aleatorio es un pacto recíproco, cuyos efectos en cuanto a las utilidades y a las pérdidas, bien sea para todas las partes contratantes, bien para una o más de ellas, dependen de un suceso incierto. Tales son, El contrato de seguro". No hay más que este artículo. Debemos necesariamente recurrir a las posibles fuentes epigonales del Código de Comercio Frances. Revisadas las obras de algunos juristas franceses -como D'Emigron, Lyon-Caen y Renaut-18, llegamos a Pothier quien en su Tratado de Aseguración o Seguros señala:

"El contrato de aseguración es aquel por el cual uno de los contrayentes se encarga del riesgo de los casos fortuitos a que está la cosa expuesta, obligándose a indemnizar al otro, si tales accidentes ${ }^{19}$ se verifican, mediante una suma que el otro contrayente le da ó se obliga a darle por precio de ese riesgo que toma a su cargo; el contratante que se encarga de los riesgos se llama asegurador, y el otro asegurado, la suma que el asegurado da ó se obliga a dar al asegurador por el precio del riesgo se llama prima de seguros; la escritura de este contrato se llama póliza de seguros. Es una especie de contrato de compra y venta: los aseguradores son los vendedores, el asegurado el comprador: la cosa vendida es la seguridad contra los riesgos a que está expuesta la cosa asegurada" 20 .

Luego Pothier al tratar las cosas que son de la esencia del contrato de seguro hace referencia al riesgo, señalando que el asegurador carga por el contrato de aseguración con los riesgos de cualesquiera casos fortuitos que pueden sobrevenir durante el viaje, y causar al asegurado una pérdida de las cosas aseguradas ${ }^{21}$.

Luego este jurista al tratar cuales son las pérdidas y perjuicios de que no responden los aseguradores, regla primera señala que "los aseguradores no responden de las pérdidas, daños y perjuicios acaecidas por culpa del capitán 
y marineros. Aunque los aseguradores no responden de tales pérdidas y perjuicios, pueden obligarse a ello por un pacto particular" 22 .

Nos queda claro que Pothier, considera al riesgo que puede asumir el asegurador como la pérdida proveniente del caso fortuito; sin embargo no pretende estructurar una norma prohibitiva o excluyente de otros riesgos, ya que el asegurador por pacto expreso puede asegurar riesgos provenientes de actos culposos del asegurado.

Podemos concluir entonces, que en cuanto a las fuentes epigonales del artículo materia de este trabajo, Ocampo consideró:

- Como fuente epigonal doctrinaria la obra de González Huebra.

- Como fuente epigonal doctrinaria la obra de Alejandro de Bacardí.

- A pesar de no existir una nota marginal de Ocampo, sin duda consideró como fuente epigonal la obra de Pothier sobre el Contrato de la Aseguración; ello a lo menos debe considerarse como fuente indirecta, ya que la codificación francesa y la obra de Pothier influyeron notablemente en los procesos de fijación de toda Europa.

- Como fuentes epigonales legales, el Código Civil y de Comercio Franceses.

\section{EL RIESGO: COMPARACIÓN DE DERECHOS}

Antes de referirnos al concepto de riesgo elaborado por la doctrina nacional y comparada, enunciaremos lo que dispone el texto actual del artículo 513 inciso segundo del Código de Comercio, la propuesta del proyecto de la Superintendencia de Valores y Seguros, el Proyecto que actualmente se tramita en el Congreso Nacional (elaborado por Osvaldo Contreras Strauch), y los comentarios efectuados por la comisión de trabajo del comité jurídico de la Asociación de Aseguradores de Chile. Los textos son los siguientes:

- Artículo 513 actual dispone: "Se entiende por riesgo la eventualidad de todo caso fortuito que pueda causar la pérdida o deterioro de los objetos asegurados".

- Artículo 513 del proyecto de la S.V.S: Riesgo asegurado, es el evento previsto en la ley o el contrato, que hace exigible la indemnización o la prestación convenida.

- Artículo 513 del proyecto de Contreras: Riesgo, la eventualidad de un suceso que ocasione al asegurado o beneficiario una pérdida o una necesidad susceptible de estimarse en dinero.

- La comisión de trabajo de la Asociación de Aseguradores en sus observaciones señala: Riesgo, toda eventualidad que pueda causar una pérdida o deterioro al bien asegurado; al patrimonio; y a la vida e integridad física o intelectual de una persona. No constituye riesgo la actuación dolosa del asegurado. 
La doctrina tanto nacional como extranjera, han elaborado diversas definiciones de riesgo. Osvaldo Contreras lo define como la posibilidad o eventualidad de que ocurra un hecho que perjudique económicamente al asegurado, ya sea porque pueda afectar a bienes determinados, al derecho a exigir ciertas prestaciones, al patrimonio mismo en forma indeterminada, o a la vida, salud o integridad de una persona ${ }^{23}$. En nuestra doctrina nacional Juan Achurra Larraín define el riesgo como la posibilidad de ocurrir un evento desfavorable que provoca una necesidad de tipo económico ${ }^{24}$. Por su parte Claudio Barroilhet define al riesgo como la posibilidad que ocurra un evento generalmente fortuito e impredecible, que es desfavorable o dañoso para el asegurado 25 .

En nuestro análisis de la doctrina extranjera, citamos al jurista español Joaquín Garrigues quien al tratar el riesgo señala que es la posibilidad de que ocurra un hecho que produzca una necesidad patrimonial; soportar el riesgo implica sufrir las consecuencias económicas de la realización del hecho previsto como posible. Para este autor la posibilidad, la incertidumbre y el azar son los elementos que integran el riesgo. Debe existir la posibilidad de que ocurra un hecho dañoso o surja una necesidad patrimonial. Si la esencia del seguro consiste en poner lo seguro en lugar de lo inseguro, para que, lógicamente exista esta institución tiene que haber alguna inseguridad 0 incertidumbre. Nadie busca un seguro contra acontecimientos imposibles; nadie lo concede contra acontecimientos ciertos. El azar importa que la realización del hecho previsto ${ }^{26}$ ha de ser fortuita, pero no en sentido absoluto (fortuito es todo lo que no está causalmente fundado), sino relativo (fortuito es todo lo que es independiente de la voluntad de la persona amenazada por el hecho previsto como posible) ${ }^{27}$. Por su parte, Fernando Sánchez Calero define el riesgo como la posibilidad de un evento dañoso. De esta definición resultan dos elementos esenciales: la posibilidad y el evento dañoso. Con relación a la posibilidad se dice que ha de referirse a un evento futuro e incierto ${ }^{28}$. El autor español José Miguel Embid Irujo señala que el riesgo, entendido como la posibilidad de un acontecimiento dañoso que haga surgir una necesidad patrimonial, se nos muestra así, como un elemento causal de todo contrato de seguro 29 .

El jurista italiano César Vivante al referirse a las características del riesgo señala que por lo común debe referirse a un evento futuro que tiene que ser incierto, al menos en cuanto al momento en que habrá de producirse; el riesgo debe ser independiente de la voluntad del asegurador, y para hacerlo tal, hay que hacer que decaiga todo derecho de quien voluntariamente provoca el siniestro. Este autor señala que el asegurador puede hacerse cargo de riesgos que tengan su origen en conductas culposas del asegurado, con tal que estos últimos tomen las cautelas necesarias que hubiesen adoptado si no estuvieran seguros de la indemnización ${ }^{30}$.

Antigono Donati parte definiendo el riesgo como la posibilidad de un evento dañoso, ello en sentido estricto. Luego sostiene que más que definir el riesgo como un evento futuro e incierto, es decir posible, conviene definirlo como la posibilidad de un evento. Este jurista sostiene que, desde un punto 
de vista jurídico, el riesgo contiene dos elementos: la posibilidad y el evento dañoso ${ }^{31}$. En la definición del elemento de la posibilidad Donati señala: "Hay imposibilidad cuando un determinado hecho es excluido de poder verificarse. Hay posibilidad cuando no se ve ni imposibilidad ni necesidad, es decir, no está excluido, ni es seguro que el evento se verifique. La posibilidad se resume en dos conceptos: futuro e incertidumbre, es lo que denomina como posibilidad objetiva; cuando el evento se verificó, pero se desconoce al momento de contratar, el seguro tendrá efecto retroactivo hay riesgo, ya que si bien no aparece el carácter futuro del evento, si existe incertidumbre, es lo que denomina como posibilidad subjetiva. La relevancia jurídica de la posibilidad se traduce en la dependencia del evento que trabaja como presupuesto incierto, cuya falta o cesación, produce la nulidad o resolución del contrato". Sobre la posibilidad de asegurar hechos o conductas culposas o dolosas, Donati en su análisis sobre el caso fortuito o forzad Maggiore señala: "La legislación y la doctrina están de acuerdo en excluir la obligación del asegurador de la hipótesis de la culpa o dolo del contratante, asegurado o beneficiario. Sin embargo cierta resistencia legal, admitió el seguro por convención expresa del evento provocado por culpa o dolo del responsable, precisamente porque no se trata de una culpa directa del interesado, pero sí de una culpa in eligiendo o in vigilando, es decir, de una culpa presunta". La incompatibilidad entre el concepto jurídico de caso fortuito y culpa se soluciona con el pacto o acuerdo expreso: dovrà essere expresamente d'acordo32.

Guiseppe Ferri al referirse al riesgo en el contrato de seguro señala: "El objeto del contrato de seguro es la aseguración de un riesgo, y esto es la asunción del peso económico que se determina a consecuencia de cumplirse un acontecimiento futuro e incierto, relativo a una determinada persona. La función del contrato es precisamente aquella de dar, a través la promesa del asegurador, una seguridad económica frente a la posibilidad de verificarse el acontecimiento. El riesgo es la posibilidad del cumplimiento del evento ${ }^{33}$. Por lo tanto si el evento es imposible o ya se ha verificado al momento de la conclusión del contrato, el contrato es nulo" 34 .

Los juristas franceses Picard y Besson definen el riesgo como un evento incierto, es decir, que no depende exclusivamente de la voluntad de las partes, especialmente del asegurado ${ }^{35}$. Lyon-Caen y Renaut señalan que el riesgo es un hecho que no debe depender de la voluntad de las partes ${ }^{36}$.

Finalmente, y en cuanto a las definiciones en el sistema del Common Law, específicamente en el ámbito del seguro (insurance law) se entiende por riesgo el daño o peligro de pérdidas de la propiedad asegurada, el siniestro contemplado en el contrato de seguro, entre otras acepciones. Parte de la doctrina anglosajona sostiene que el acuerdo (contrato) debe relacionarse con un riesgo, el cual involucra incertidumbre en cuanto la pérdida puede ocurrir o no, o podría ocurrir en un tiempo que no podemos predecir. En otras palabras el contrato de seguros es un contrato de especulación ${ }^{37}$. Otros autores al tratar el riesgo señalan que los reclamos en contra de los asegurados, a menos que exista un acuerdo expreso que lo excepciones, incluyen reclamos 
por negligencia. No importa si la negligencia proviene del asegurado, sus dependientes o extraños. El riesgo no se extiende a conductas intencionales del asegurado, si ha conductas dolosas de dependientes del asegurado o extraños. Por regla general el seguro es contra eventos fortuitos; el propósito de la póliza es asegurar la indemnización en contra de accidentes que pueden ocurrir, y no en contra de los que deben ocurrir ${ }^{38}$.

Volviendo al texto del artículo 513 del Código de Comercio, reiteramos que tal concepción, ha sido criticada por la doctrina nacional, ya que limita el concepto de riesgo a la ocurrencia de un caso fortuito, esto es, un imprevisto que no es posible resistir, siguiendo la definición de nuestro Código Civil. La crítica señalada, tiene como sustento lo siguiente: hoy en día no solo aquellos hechos calificables como fortuitos, pueden ser materia del contrato de seguros, sino hechos culpables del asegurado e incluso actos intencionales de terceros ${ }^{39}$. La interrogante será, si la expresión caso fortuito, debe entenderse en el sentido del artículo 45 del Código de Bello.

\section{LA MODIFICACIÓN: ¿ES NECESARIA?}

Del breve análisis de las fuentes epigonales y de la comparación de derechos, se puede concluir que la definición de nuestro Código -texto actual- no es del todo inexacta, de hecho contiene los elementos esenciales de los que nos habla la doctrina: eventualidad (posibilidad), incertidumbre y daño. ¿Es necesario entonces modificar esta norma? La pregunta surge ya que la elaboración de los Códigos decimonónicos fue la conclusión de un extenso proceso científico de fijación de derecho ${ }^{40}$. Guzmán Brito al analizar la fijación del derecho legal señala: Un código legislativo tendrá pleno éxito si se basa en trabajos científicos previos, cuyo contenido sintetizador, cuyo sistema comprensivo, cuya amplitud de tratamiento de instituciones y problemas, provengan del hecho de ser esos trabajos precisamente epigonales respecto de una dilatada actividad anterior ${ }^{41}$.

Lo expuesto es de fundamental relevancia, ya que nos preguntamos si los proyectos de modificación del Código de Comercio que ya se han citado, se sustentan en alguna o algunas obras epigonales, y obedecen a alguna corriente científica o escuela de pensamiento. Ello a nuestro entender es fundamental, ya que si la fijación se sustentó en obras epigonales y obedecen a corrientes científicas, las modificaciones que posteriormente se materialicen deben obedecer necesariamente al mismo criterio. Esto no puede tratarse de cambios de articulado, modificación de los mismos o derogaciones completas de un código o partes de él. En este sentido el proyecto que actualmente se tramita en nuestro Congreso Nacional nos parece exageradamente pretencioso, ya que reemplaza el Título VIII del Libro Segundo del Código en su totalidad. Llama la atención que este proyecto parte con un mensaje, y continúa con una explicación de la estructura de la nueva normativa, sin citar fuente alguna, solo se recurre a la expresión corriente mayoritaria.

Finalmente y como dice De los Mozos, un Código es algo más que un reglamento o una ordenanza, el creer lo contrario supone una visión de un 
positivismo tan degradado que ni siquiera es imaginable pueda ser concebido por un jurista. Efectivamente, un Código está pensado, diríamos, para hacer frente a las necesidades coyunturales que suscitan las leyes especiales, o a las reformas que introducen las novelas, lo mismo que lo está para ser interpretado, en uno u otro sentido, por la doctrina y por la jurisprudencia, de manera que, al cabo de los años, una misma norma puede dar lugar a aplicaciones distintas ${ }^{42}$.

\section{ARTÍ́CULO 513 DEL CÓDIGO DE COMERCIO, TEXTO ACTUAL: UNA PROPUESTA DE REINTERPRETACIÓN}

Caso fortuito, case fortuit, act of god, son las distintas denominaciones que encontramos en nuestro sistema y en la comparación de derechos. En el ámbito del seguro, nos parece que el concepto de caso fortuito no debe ser aplicado en el estricto sentido del artículo 45 de nuestro Código Civil. En tal sentido Claudio Barriolhet Acevedo está en lo correcto al señalar que la posibilidad se relaciona con el carácter fortuito del riesgo. Este autor cita a Ruiz Soroa, quien señala que el término fortuito no puede ser aplicado en su correcto sentido jurídico cuando nos movemos en el campo del seguro, so pena de vaciar de contenido el contrato en gran medida: en efecto, quedarían fuera de cobertura todos los actos de origen humano doloso o culposo (del asegurado, de sus dependientes o terceros), lo que, desde luego, no quiere decir la norma, cuando se remite a lo fortuito. En puridad aseguradora, el término fortuito de contrapone a inevitable, al no riesgo 43 .

Consideremos entonces que es asegurable todo caso fortuito, así fue comprendido históricamente el contrato de seguro en sus inicios; sin embargo la evolución legal y doctrinaria han permitido la aseguración de hechos que tienen su origen en conductas culposas del asegurado, e incluso culposas y dolosas de terceros. En un principio la doctrina señaló que el riesgo debe ser independiente de la voluntad de asegurado. Ello debemos entenderlo como el acto no intencional. Así lo señalan numerosos autores como Manresa Navarro, Lyon-Caen y Renaut, Picard y Benson, Vivante, Garrigues, entre otros.

A la luz del análisis histórico y doctrinario realizado hasta ahora, nuestra propuesta de reinterpretación contempla dos vías (compatibles entre sí). Son las siguientes:

- La definición que contiene el artículo 513 inciso segundo del Código de Comercio, al usar el término caso fortuito, debe ser entendida como lo incierto e inevitable (en concepto de Ruiz Soroa y Garrigues). Es decir, tal expresión solo busca excluir del seguro los actos intencionales o dolosos del asegurado.

- Debe considerase el término caso fortuito del artículo 513, como una definición meramente ilustrativa, pero no excluyente de los actos culposos del asegurado o culposos e intencionales de terceros. Para dar mayor veracidad y sustento a esta interpretación, recurriremos a la analogía. El artículo 552 del Código de Comercio dispone: "El 
asegurador no está obligado a indemnizar la pérdida o deterioro procedentes de vicio propio de la cosa, de un hecho personal del asegurado o de un hecho ajeno que afecte civilmente la responsabilidad de este". La norma no es prohibitiva, solo expresa que el asegurador no está obligado a garantizar o amparar los daños que provienen, entre otros, de hechos personales del asegurado (debe entenderse como hechos culpables) o de hechos de terceros.

En consecuencia, y como dice Pothier y luego Donati, tales hechos pueden ser asegurados, siempre que ello se pacte expresamente.

Nuestra tesis se refuerza con lo siguiente: "El Código de Comercio en su artículo 4 admite como fuente de derecho la costumbre fuera de la ley praeter legem-, y ello se condice con la realidad actual que ha incorporado diversos modelos de pólizas ${ }^{44}$, que incluyen coberturas por riesgos no constitutivos de caso fortuito, sino hechos culpables y propios del asegurado, como actos culposos e intencionales de terceros. Ocurre esto, en especial, en los modelos de pólizas de responsabilidad civil ${ }^{45}$.

\section{CONCLUSIONES}

1. Las modificaciones que se pretendan introducir a los códigos decimonónicos, deben sustentarse no solo en supuestas necesidades impuestas por la realidad económica y social, sino que además, en corrientes científico jurídicas o de pensamiento jurídico que durante un determinado periodo de tiempo, generalmente prolongado, han sentado las bases, principios y criterios que inspiran las nuevas normativas. Consideremos recurriendo a las expresiones de Guzmán Brito, en su obra Historia Literaria del Código Civil de la República de Chile, que el Código de Comercio es un "Libro de Derecho" 46.

2. En concordancia con lo anterior parece más razonable una reinterpretación del artículo 513 inciso segundo del Código de Comercio, considerando lo fortuito como lo incierto y no intencional, lo que permitiría la asegurabilidad de lo imprevisto e irresistible, las conductas culposas del asegurado e incluso culposas y dolosas de terceros. Por lo demás, ello concuerda con lo expuesto por Pothier, Donati y tantos otros, quienes señalan que el asegurador puede obligarse por pacto particular a la asunción de riesgos proveniente de conductas culposas del asegurado.

3. Como Colofón señalamos lo siguiente: "En cuanto al aseguramiento de los riesgos relacionados con la responsabilidad civil del asegurado, es evidente que el término caso fortuito no solo se hace insuficiente, sino excluyente de la asegurabilidad de la responsabilidad civil, ya que constituye una causal de exoneración del responsable del daño". Recordemos el actual principio de reparación: "Quien causa un daño a otro estará obligado a repararlo cuando no concurra una razón suficiente que justifique que sea el perjudicado quien haya de soportarlo". Constituyen una razón suficiente (i) culpa de la propia víctima en el origen del daño, (ii) fuerza mayor, caso fortuito o eximentes de responsabilidad en los casos especiales 
Por ello, insistimos en que por pacto expreso, cabe la asegurabilidad de la responsabilidad civil. Ello no constituye una infracción a lo dispuesto en el artículo 513 inciso segundo del Código de Comercio.

\section{BILBIOGRAFÍA CITADA}

AchURRA, Larraín Juan (2005) Derecho de Seguros, escritos de Juan Achurra Larraín (Universidad de los Andes, Colección Jurídica 7). Tomo III.

Avecilla, Pablo (1849). Diccionario de la Legislación Mercantil de España. (Universidad de Sevilla - España).

BACARDI, Alejandro (1840) Tratado de Derecho Mercantil de España.

BAEZA, Sergio (2001) El Seguro (Editorial Jurídica de Chile).

Brahm, García Enrique (2000) José Gabriel Ocampo y La Codificación Comercial Chilena (Colección Jurídica № 5 de la Universidad de los Andes).

BARRIOlhet, Acevedo Claudio (2007) Derecho de Seguro Marítimo (Editorial Librotecnia).

Bataller, Latorre y Olavarría (2007) Derecho de los Seguros Privados (Editorial Marcial Pons - Madrid - España).

BRUNETI, Antonio (1951) Derecho Marítimo Privado Italiano (Editorial Bosch Barcelona - España - Traducción de Gay de Montellá).

Carmona, Tamayo Juan (1997) Falta de Cumplimiento y Responsabilidad en la Obligación de Dar. (Publicaciones Universidad de Valencia).

Carreras y GonzÁlez, Mariano (1860) Elementos del Derecho Mercantil de España.

Claro, Solar Luis (1988). Explicaciones de Derecho Civil Chileno y Comparado, Volumen V, De Las Obligaciones. (Editorial Jurídica de Chile).

Castellano, Gaetano (1970) Le Assicurazione Private (Unión Tipográfico Editrice Torinece) p. 174.

CONTRERAS, Osvaldo (2002). El contrato de Seguro (Editorial La ley).

CONTRERAS, Osvaldo (2004) Instituciones de Derecho Mercantil (Editorial LexisNexis) pp. 40-41

Colinvaux, Raoul (1970) The Law of Insurance (London Sweet \& Maxwell Limited).

D'EmIGRON, (1827) Traité des Assurances et des Contrat a la Grosse.

DE LOS Mozos, José Luis (1987) El Negocio Jurídico (Editorial Montecorvo España).

DonATI, Antigono (1954). Trattato del Diritto delle Assicurazionni Private, Volume Secondo (Editore Guiffré).

EmBID, Irujo José Miguel (2002). Comentarios a la Ley de Contrato de Seguro (Obra editada por el Departamento de Derecho Mercantil de la Universidad de Valencia - España).

Elguero, Merino José María (2004) El contrato de Seguro (Fundación Mapfre).

FERRI, Giuseppe (1970) Manuale di Diritto Commerciale (Unión Tipográfico Editrice Torinece). 
García, Goyena Florencio (1852) Concordancias del Código Civil Español. GARRIGUES, Joaquín (1987) Curso de Derecho Mercantil. Tomo IV (Editorial Temis).

GonzÁlez Huebra, Pablo (1859) Curso de Derecho Mercantil, Tomo I.

GuZMÁN, Brito Alejandro (1977). La Fijación del Derecho (Ediciones Universitarias de Valparaíso, Universidad Católica de Valparaíso).

Guzmán, Brito Alejandro (2005). Historia Literaria del Código Civil de la República de Chile.

LASSO, Gaité Juan Francisco (1970) Crónica de la Codificación Española.

LeÓn y OlaRIETA, Fernando (1856) Manual de Jurisprudencia Popular.

LOWRY, John y RAWLING, Philip (2005) Insurance Law, Doctrines y Principles

(University College London) p. 3.

LyON-CAen y Renaut (1912) Traité de Droit Commercial (Libraire Générale de Droit et de Jurisprudence).

ManResa y Navarro, José María (1907). Comentarios al Código Civil Español (Imprenta de la Revista de Legislación - Madrid).

MARTínez, Alcubilla Marcelo (1867) Diccionario Manual de Derecho Civil . Mıccio, Renato (1966) Dei Singoli Contrati (Torino - Unione Tipografica Editrice Torinece).

PCARD, Maurice y BESSON, Andre (1964). Les Assurances Terrestres en Droit Francais (Librería General de Derecho y Jurisprudencia, R. Pichon y R Duranz Auzias).

POTHIER, Joseph (1848). Tratado del Contrato de Compra y Venta. (Traducción de la Sociedad de Amigos Colaboradores, Barcelona España). POTHIER, Joseph (1845). Tratado del Contrato de Aseguración o Seguros. (Traducción de la Sociedad de Amigos Colaboradores, Barcelona España).

Reglero, Campos Fernando (2006) Tratado de Responsabilidad Civil (Editorial Thomson - Aranzadi-Madrid-España).

Sandoval, López Ricardo (2007) Derecho Comercial, Tomo III, V 1 (Editorial Jurídica de Chile).

SÁNCHEZ, Calero Fernando (2005) Ley de Contrato de seguro (Editorial Thomson Aranzadi).

TIRADO, Suárez Francisco Javier (1992) Derecho Mercantil (Editorial Ariel Barcelona)

URIA, Rodrigo (1969) Derecho Mercantil (Universidad de Madrid)

VivANTE, César (1952) el Contrato de Seguro (Traducción de Santiago Sentís Melendo - Ediar - Buenos Aires Argentina).

* Licenciado en Ciencia Jurídicas y Sociales, Pontificia Universidad Católica de Chile; y Doctorando de la misma Universidad; Abogado Miembro de la Asociación Internacional de Derechos del Seguro (AIDA), sección chilena; Becario Conicyt; Facultad de Derecho, Avenida Libertador Bernardo O’Higgins 340, Tercer piso, Santiago; Correo electrónico: rrios@uc.cl

1 Se omite lo siguiente: El mensaje del Presidente José Joaquín Pérez señala: "En su primera parte describe el seguro en abstracto, se definen las palabras de más uso frecuente en la materia y se exponen, con la distinción que exige su novedad entre nosotros, los principios comunes al seguro terrestre y marítimo, siguiendo la huella de la legislación de las naciones que por mucho tiempo han practicado este contrato". Tiene suma relevancia lo 
dicho, ya que como señalaremos más adelante, las fuentes epigonales, legales y doctrinarias que influyeron en Ocampo son riquísimas y variadas. Ya esta parte del mensaje nos da luces, en cuanto a que las legislaciones de países europeos influyeron en nuestro Código de Comercio.

2 Ver CONTRERAS (2002) p. 18.

3 BRAHM (2000) pp. 27-40. El historiador y abogado Enrique Brahm García es autor una magnífica obra de recopilación publicada bajo el título José Gabriel Ocampo y La Codificación Comercial Chilena. En este trabajo podemos apreciar las riquísimas fuentes epigonales que inspiraron a Ocampo y nos permite precisar la opinión del profesor Osvaldo Contreras -autor chileno que sostiene que las actas de la Comisión Revisora de nuestro código se han perdido, impidiendo así un estudio histórico de tal código-, en el siguiente sentido: A la fecha de dictación de nuestro Código de Comercio, encontramos vigentes los Códigos de Comercio de Francia, el español de 1829, el portugués de 1833, el holandés de 1838, el Allgemeine Landrecht prusiano de 1794, Las Ordenanzas de Bilbao, el proyecto de Código de Comercio español del 1851. A ello debemos sumar la gran cantidad de obras epigonales como las de Pothier, D’Emigron, González Huebra, Alejandro de Bacardí, Pablo Avecilla, entre otros.

4 Vid todos. Pothier (1848) p. 157; Carmona (1997) p. 241.; Abeliux (1993) p 983; Claro SOLAR (1988) p. 679.

Hay evidentemente una similitud en el tratamiento del concepto de riesgo contractual y el riesgo en su acepción asegurativa: la pérdida económica; sin embargo en el segundo caso el concepto de riesgo advierte una concepción mas extensa, ya que no se limita al cumplimiento contractual.

5 González Huebra (1859) p. 303; Idem León y Olarieta (1856) p. 411; Carreras y GONZÁLEZ, (1860) p.204.

${ }^{6}$ Avecilla (1849) p. 304; Idem Martínez (1867) p 127.

7 BACARDí (1840) p. 358.

8 BACARDí (1840) p. 362.

9 Son un precedente y posible fuente legal epigonal del Código de Comercio Español de 1829 las Ordenanzas de Bilbao (Ordenanzas Sobre Seguros Marítimos de 1484), que parten señalando: "Respecto de que en este comercio se acostumbran hacer varios contratos de seguros, así por mar como por tierra, que consisten en tomar a su cargo los aseguradores el riesgo, daño, y contingencias en casos fortuitos; es a saber, por lo que mira al mar, de naufragios, averías, echazones, presas de enemigos, retenciones de príncipes, baratería de patrón y marineros, incendios, y otras adversas fortunas que pueden acaecer pensada o impensadamente a las mercaderías y otras cosas, obligándose a pagar al asegurado las cantidades que expresaren las pólizas". También podríamos considerar como fuente epigonal legal Las Ordenanzas para los Seguros Marítimos del Magistrado de Barcelona de 1458 que usa la expresión riesgo o peligro, no así la expresión caso fortuito; Las Ordenanzas para Seguros Marítimos de Burgos de 1537 que hace uso de la expresión correr riesgo.

10 Ver BACARDí (1840) p. 384.

${ }^{11}$ Es importante señalar que el proyecto de Código Civil español de García Goyena no llegó a puerto.

12 García Goyena, (1852) pp. 110-111.

13 LASSO (1970) p. 277.

14 Nótese la similitud de ubicación con el Code Civil, que trata los contratos aleatorios en el Título XII.

15 Vid cita 9.

16 MANRESA (1907) pp. 11-26.

17 El texto analizado es el vigente a la época de elaboración y dictación de nuestro Código de Comercio, y no el texto actual.

18 Lyon-Caen y Renaut. (1912) p. 252; D'Emigron (1827) p. 6. Este último constituye fuente epigonal del artículo 513 inciso tercero de nuestro código de comercio.

19 Nótese que la expresión accidentes el usada por González Huebra al definir el riesgo como "todos los accidentes que pueden ocurrir". A su vez Bacardí al definir el riesgo habla de "accidentes o casos fortuitos".

20 Pothier (1845) p. 5; Estimados que la influencia de Pothier en González Huebra y Bacardí es evidente, basta con analizar las definiciones que dan de asegurado, asegurador y prima, así como la propia definición del riesgo. 
21 POTHIER (1845) p. 6.

22 POTHIER (1845) pp. 5, 6, 22-23.

23 Contreras (2002) p. 18.

24 Achurra (2005) p. 8; Idem Baeza (2001) p. 69; Sandoval, (2007) p. 198.

25 BARRIOLHET (2007) p. 147.

26 Previsto debe entenderse como lo establecido o acordado por las partes y no en sentido de previsibilidad, es decir, aquello que se puede o no conocer con anticipación.

27 Garrigues (1987) p.p. 251-252; Idem URIA (1969) p. 553; Elguero (2004) p. 4.

28 SÁNCHEZ (2005) p. 117; Idem TIRAdo (1992) p. 556; BATALLER, LATORRE y OlavarRía (2007)

p. 174; ver REGLERO (2006) pp. 733 a 734.

29 EMBID (2002) p. 53.

30 VIVANTE (1952) pp 18 a 25.

31 Donati (1954) p. 111-121-122. Idem Castellano (1970) p. 174; Bruneti (1951) p. 432.

32 DONATI (1954) p. 124.

33 Idem DONATI (1954) p. 111.

34 FERRI (1970) p. 723; Idem Miccio (1966) pp. 399-400.

35 PCARD Y BESSON (1964) p. 33.

36 LYON-CAEN y RENAUT (1912) p. 252.

37 LOWRY y RAWLING (2005) p. 3.

38 Colinvaux (1970) pp. 59-60.

39 Vid todos, Contreras (2002) p. 18; Sandoval (2007) p.p. 198-199; Baeza (2001) p. 70.

40 GUZMAN BRITO (1977) p. 53.

41 GUZMAN BRITO (1977) p. 33.

42 De los Mozos (1987) p. 43. A propósito de la crítica de la doctrina italiana al Codice Civile, y la teoría de constitucionalización del derecho.

43 BarRiolhet (2007) p. 148; Idem GarRigues (1987) p. 251.

44 El mecanismo de depósito y comercialización de pólizas está regulado en la norma de carácter general número 124, de fecha 22 de noviembre del 2001, dictada por la S.V.S en el ejercicio de su actividad reguladora, y según lo dispone el artículo 3 letra e del DFL 251. Según esta normativa se distingue en todo contrato de seguros o póliza los denominados condicionados particulares y los condicionados generales; los primeros varían caso a caso y contienen los datos como individualización de las partes, prima, monto de las coberturas, vigencia, descripción de la materia asegurada o giro del asegurado, etc. Los segundos son los modelos de póliza depositados en la Superintendencia, y contienen las cláusulas que definen los riesgos cubiertos, las modalidades de cobertura, las exclusiones de cobertura y una serie de cargas impuestas al asegurado cuyo incumplimiento generan la pérdida de este último a reclamar el pago de la indemnización. Los condicionados generales, a su vez, se clasifican en pólizas madres o principales (denominada POL) y cláusulas adicionales (denominadas CAD) las que dejan sin efecto las exclusiones de las pólizas principales.

45 A modo de ejemplo el condicionado general sobre responsabilidad civil, inscrita en el Registro de Pólizas de la S.V.S bajo el código POL 191 086, al definir la cobertura, dispone en su artículo $1^{\circ}$ : En consideración a la propuesta de seguro que contiene las informaciones que sirven de base para la emisión de esta póliza y que forma parte integrante del contrato de seguro, y siempre que la prima estipulada en las Condiciones Particulares de esta póliza haya sido pagada o documentada, la compañía garantiza al asegurado el pago: 1.1 De las indemnizaciones pecuniarias de que, con arreglo a los Artículos pertinentes del Código Civil y con relación a los riesgos designados en las Condiciones Particulares, puede resultar civilmente responsable por: 1.1.1 la muerte de terceras personas o las lesiones corporales causadas a las mismas (lesiones corporales); 1.1 .2 los daños causados a cosas pertenecientes a terceras personas (daños materiales), que se produzcan durante la vigencia de la presente póliza.

La cláusula de responsabilidad civil patronal, adicional a la póliza de responsabilidad civil inscrita en el registro de pólizas bajo el código pol 191 086, inscrita en el registro de pólizas bajo el código cad 193 051, establece que el presente adicional es una extensión de la cobertura establecida en la póliza de responsabilidad civil de la cual forma parte. No obstante cualquier condición o exclusión indicada en la condiciones generales de esta póliza, el seguro contratado se extiende a cubrir en virtud de este adicional, a los asegurados, sus representantes, apoderados, o cualquier otra persona que colabore con ellos en la dirección o vigilancia de la empresa, los cuales para estos efectos tienen la 
calidad de asegurados, por: 1. Las indemnizaciones en dinero que se vean obligados a pagar por la responsabilidad civil extracontractual que sea declarada por sentencia judicial ejecutoriada, motivada por reclamo interpuesto por el trabajador, sus sucesores o beneficiarios, a causa de un accidente del trabajo del cual un trabajador del contratante ha resultado con lesiones corporales o le ha causado la muerte.

46 GuZMÁn BRITo (2005) p. 9. 